\title{
Permanent Dental Restoration
}

National Cancer Institute

\section{Source}

National Cancer Institute. Permanent Dental Restoration. NCI Thesaurus. Code C60719.

A replacement for a lost tooth structure designed for continued or prolonged use. 